5. Brace RA 1989 Effects of outflow pressure on fetal lymph flow. Am J Obstet Gynecol 160:494-497

6. Brace RA 1989 Thoracic duct lymph flow and its measurement in chronically catheterized sheep fetus. Am J Physiol 256:H16-H20

7. Vieth E 1989 Fitting piecewise linear regression functions to biological responses. J Appl Physiol 67:390-396
8. Drake RE, Giesler M, Laine GA, Gabel JC, Hansen TN 1985 Effect of outflow pressure on lung lymph flow in unanesthetized sheep. J Appl Physiol 58: $70-76$

9. Olszewski WL, Engeset A 1985 Studies on the lymphatic circulation of humans. In: Johnson MG (ed) Experimental Biology of the Lymphatic Circulation. Elsevier, New York, pp 395-422

\title{
Announcement
}

\section{Search for Editor-in-Chief \\ Pediatric Research}

After 5 years of service, the American Editorial Board of Pediatric Research will complete its term on December 31, 1993. The Board of Trustees of the International Pediatric Research Foundation, Inc. has established a Search Committee to review the credentials of qualified candidates for a new Editor-in-Chief and to make recommendations to the Board, which has the responsibility for final selection.

The Search Committee seeks candidates or recommendations for individuals who might serve as Editor-inChief. The office carries a budget for supporting staff and an honorarium. Interested individuals should submit six copies of their curriculum vitae and those of at least four individuals in their locale to serve as editors. In addition, the application should include a statement of goals, expectations, and future plans for the growth of Pediatric Research as a unique biomedical publication. The Search Committee will interview selected candidates immediately before the annual meeting of the Board of Trustees in early May 1993. Applications should be sent, before January 1, 1993, to: Thomas N. Hansen, M.D., Department of Pediatrics, Baylor College of Medicine, One Baylor Plaza, Houston, TX 77030. 